\title{
ARTICLE
}

\section{Practice for reducing contamination of controlled area under the influence of Fukushima nuclear accident}

\author{
Hiroshi Yoshitomi*, Yosuke Tatebe, Keiichi Kawai and Munehiko Kowatari \\ Japan Atomic Energy Agency, 2-4 Shirakata, Tokai-mura, Naka-gun, Ibaraki-ken, 319-1195, Japan
}

\begin{abstract}
The Facility of Radiation Standards (FRS) of the Japan Atomic Energy Agency provides various radiation fields for calibration and testing. Radioactive materials discharged by the Fukushima nuclear accident contaminated around the FRS including inside radiation controlled areas, even though the FRS is located 120 $\mathrm{km}$ away from there. A month after the accident, the maximum contamination level in the controlled areas was $7.3 \mathrm{~Bq} / \mathrm{cm}^{2} .{ }^{134} \mathrm{Cs},{ }^{137} \mathrm{Cs},{ }^{131} \mathrm{I},{ }^{132} \mathrm{Te}$ and ${ }^{132} \mathrm{I}$ were identified by $\gamma$-ray spectrometry. As for the FRS, practices for reducing contamination in the controlled areas were indispensable to keep the facility running under contaminated environment. The following two practices were found to be effective: 1) decontamination by wiping out with a wet cloth or steam cleaners, and 2) to prevent dust with contaminants from entering into the controlled areas. As a result, contamination inside the controlled areas decreased and was maintained to be dozens of times lower as compared with the outside.
\end{abstract}

Keywords: Fukushima Dai-ichi Nuclear Power Station accident; decontamination; surface contamination; radiation protection

\section{Introduction}

The Facility of Radiation Standards (FRS) of the Japan Atomic Energy Agency (JAEA) has been making significant contributions to calibrations of radiation measuring instruments in Japan. The FRS is three-storied, one basement building with reinforced concrete structure, with a building area of $4153 \mathrm{~m}^{2}$. Calibration fields for $\mathrm{X}$-, $\gamma$-, $\beta$-rays and neutrons have been installed and operated there. In order to produce radiation fields, stainless-steel-encapsulated radiation sources, the particle accelerator, and X-ray generators are mainly used inside radiation controlled areas, which are strictly regulated by laws. Since only sealed sources are used in the controlled areas mentioned in this paper, in normal situation no radioactive contamination would be taken into account, and contamination control such as an airtight installation, changing clothes and shoes, and monitoring contamination of workers or stuff is not required.

The Nuclear Science Research Institute (NSRI) of JAEA including the FRS is located in Tokai-mura, Ibaraki prefecture, Japan, about $120 \mathrm{~km}$ south of the Fukushima Dai-ichi Nuclear Power Station (FDNPS). On 11th March 2011, an enormous earthquake (The Great East Japan Earthquake) and subsequent tsunami struck a wide area of northeastern Japan. As with the other regions of northeastern Japan, utilities and

*Corresponding author. Email: yoshitomi.hiroshi@jaea.go.jp installed apparatus in the FRS has severely damaged. The earthquake and subsequent tsunami also triggered the Fukushima nuclear accident. As a consequence, massive amounts of radioactive materials have been released from the FDNPS into the environment.

Radioactive deposition due to the Fukushima nuclear accident has been observed in Tokai-mura [1]. Not only ground around the FRS but the controlled areas inside the FRS were found to be contaminated as well. However, the FRS had to be restored and operated again even in such a situation. This was because the FRS was asked to play a critical role in calibrating dosemeters used for monitoring and remediation of large contaminated areas in Fukushima prefecture. Therefore, we had to find a way to keep the facility running as much as possible, minimizing contamination levels.

A very few studies have focused on reducing contamination in a controlled area under widespread contaminated environment. This study describes a practice for reducing contamination so that the facility can be operated even under deeply contaminated environment. The paper will also discuss effective measures we have taken for reducing the existing contamination.

\section{Material and methods}

\subsection{Policies against contamination control}

Before the resume of operation of the FRS, the 
following two policies were established for keeping the calibration works running under the contaminated environment; 1) to decontaminate the controlled areas and 2) to prevent the contaminants from coming into the controlled areas from the outside of the FRS. According to these two policies, decontamination and prevention program against radioactive contaminants were made.

\subsection{Practices of contamination control}

Practices the authors have taken in a chronological sequence are shown in Figure 1. With regard to the decontamination of the controlled areas, 1.1): wiping out contaminants on the floor and 1.2): waiting until short-lived contaminants decay were chosen. When resuming calibration works, floors in the controlled areas were decontaminated using wiping out with a wet cloth and/or steam cleaners which generate steam with a pressure of $0.35 \mathrm{MPa}$ and $100{ }^{\circ} \mathrm{C}$, every day until 10th June 2011 and every week since then. As will be described later, short-lived contaminants, namely ${ }^{131} \mathrm{I}$, ${ }^{132} \mathrm{Te}$ and ${ }^{132} \mathrm{I}$, came into the controlled areas. Waiting until short-lived contaminants decay would be rather efficient, considering limited resources available.

Before planning measures according to the second policy, the authors assumed three possible pathways for entry of contaminants. These are the entries of 2.1): the air current from the outside which would cause the deposition of radionuclide inside (especially the dry deposition of gaseous ${ }^{131} \mathrm{I}$ [3]) and transport the contaminated sand dust, 2.2): personnel who would bring in contaminants attached on their shoes or cloths, 2.3): contaminated stuff from the outside.

In order to prevent these pathways, various measures shown in Figure 1 have been undertaken. The entrance doors of the controlled areas had been close and ventilation had stopped until May to prevent the deposition of contaminants in the air. The shielding doors at the boundary of the building (see Figure 2) have been sealed up so that the air including contaminants could not enter through the interstices.

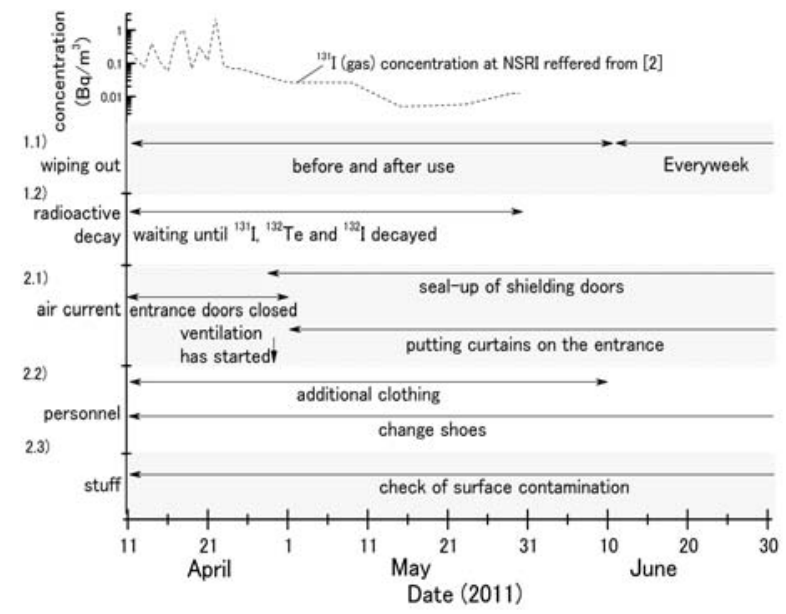

Figure 1. Time-sequence of practices for reducing contamination in the controlled areas until the end of June.

\subsection{Measurements of surface contamination density}

While these practices have been persistently engaged, intensive measurements of surface contamination densities for inside and outside of the FRS have been performed as well. The obtained results were used to review how effective decontamination and prevention measures we have taken were. One indirect and two direct measurements were applied for determining surface contamination densities. In conjunction with the measurement of surface contamination densities, activity concentrations in dust sampled around and inside the FRS were determined using high-purity germanium (HPGe) detector.

Regarding the indirect measurement for surface contamination densities on floors in the controlled areas, a smear method was employed. The smear papers (No.63 ADVANTEC) wiped up about $100 \mathrm{~cm}^{2}$ were measured using a GM tube type survey meter (TGS-133, Aloka) calibrated with ${ }^{137} \mathrm{Cs}$ standard source in advance.

With regard to the direct measurement, in-situ Ge $\gamma$-ray spectrometry and direct measurement using a proportional counter type survey meter were selected. For the in-situ measurement using an HPGe detector (GEM-40190-P-S, ORTEC), the detector was collimated with lead bricks with $10 \mathrm{~cm}$ thickness. This was because the exactly defined area $(10 \mathrm{~cm} \times 10 \mathrm{~cm})$ was to be measured and background $\gamma$-rays to be eliminated. Discussion on details of the measurement will be reported elsewhere. For the direct measurements, a portable gas proportional counter (CONTAMAT LB-122, Berthold) with wide active area $\left(210 \mathrm{~cm}^{2}\right)$ was employed. This instrument was also calibrated using a ${ }^{137} \mathrm{Cs}$ standard source in advance.

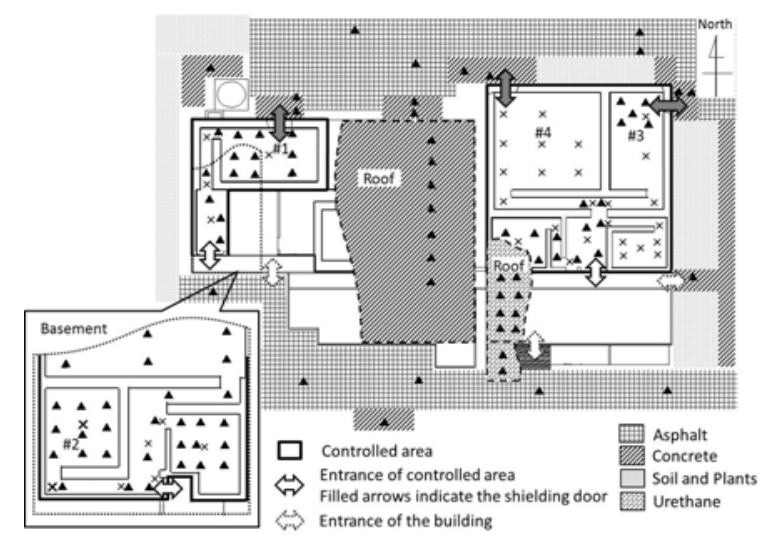

Figure 2. Schematic drawing of the FRS. The $\times$ and $\boldsymbol{\Delta}$ signs show the points smeared (see Figure 3 ) and measured by the gas proportional counter (see Figure 4) respectively.

\subsection{Initial contamination levels}

\subsubsection{Inside of the FRS}

As will be mentioned in 2.4.2, no calibration work could have been done and ventilation system for the controlled areas had not been worked for a month. On 11th April 2011, surface contamination densities for floors in the controlled areas were measured by the 
indirect measurement using smear method. The measurement results indicated the contamination spread whole the controlled areas with the level of $7.3 \mathrm{~Bq} / \mathrm{cm}^{2}$ at maximum as mentioned in 3.1.1.

\subsubsection{Outside of the FRS}

During March 2011, a large amount of radioactive materials have been observed at NSRI. The highest concentrations of aerosol-bound radiocaesiums and of volatile (or gaseous) ${ }^{131} \mathrm{I}$ were $8.52 \times 10^{2} \mathrm{~Bq} / \mathrm{m}^{3}$ and 1.37 $\times 10^{3} \mathrm{~Bq} / \mathrm{m}^{3}$, respectively [2]. The FRS could not resume the operation until the middle of April 2011, because these artificial radioactive materials in the atmosphere had been observed and the utilities and apparatuses had not been restored yet in March 2011.

\section{Results and discussion}

\subsection{Monitoring of the contamination levels}

\subsubsection{Inside of the FRS}

In order to monitor time-sequential variations of the surface contamination densities in the controlled areas inside the FRS, smear sampling at fixed points on the floor indicated by $\times$ signs in Figure 2 was made. Figure 3 shows the surface contamination densities determined by the indirect measurement. ${ }^{134} \mathrm{Cs},{ }^{137} \mathrm{Cs},{ }^{131} \mathrm{I},{ }^{132} \mathrm{Te}$ and ${ }^{132} \mathrm{I}$ were identified in a smear sample using an HPGe detector.

Even on the same day the surface contamination densities were found to vary among sampling points. For example, they distributed from detection limit (about 0.4 $\mathrm{Bq} / \mathrm{cm}^{2}$ ) to $7.3 \mathrm{~Bq} / \mathrm{cm}^{2}$ on 11th April. Then they tended to decrease over time and have been less than detection limits since the end of May. The measures against decontamination were reviewed and revised according to these results, such as the frequency of wiping-out, which lead to run the facility more efficiently. As a consequence of our practices, the contamination levels on the epoxy-coated floors of the controlled areas were less than $0.1 \mathrm{~Bq} / \mathrm{cm}^{2}$ for ${ }^{137} \mathrm{Cs}$ in September 2011, such as $0.08 \mathrm{~Bq} / \mathrm{cm}^{2}$ (\#1 in Figure 2) and $0.07 \mathrm{~Bq} / \mathrm{cm}^{2}$ (\#2 in Figure 2), determined using the Ge detector with lead shielding (the detection limit was approximately 0.01 $\mathrm{Bq} / \mathrm{cm}^{2}$ for this measurement).

These were endorsed by the measurement results of surface contamination densities inside the FRS in November 2011 using the gas proportional counter, as shown in Figure 4. A part of the measured points are shown in Figure 2. Figure 4 also shows that surface contamination densities of the doormat placed in front of the entrance door of the building were relatively higher.

\subsubsection{Outside of the FRS}

In September 2011, the surface contamination densities outside of the FRS were $2.5 \mathrm{~Bq} / \mathrm{cm}^{2}$ (northern side) and $1.8 \mathrm{~Bq} / \mathrm{cm}^{2}$ (southern side) for ${ }^{137} \mathrm{Cs}$ using the Ge detector with lead shielding.

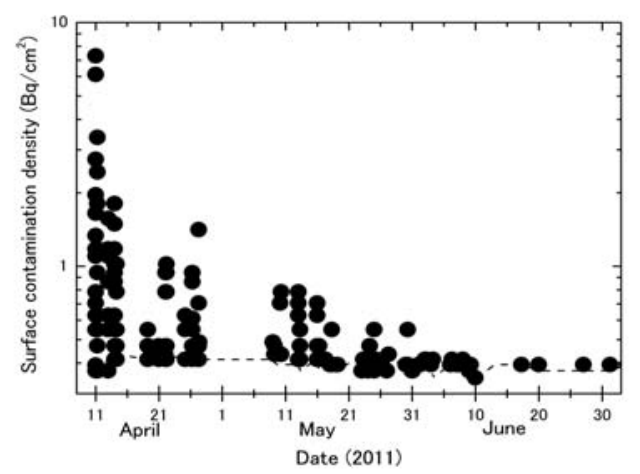

Figure 3. Surface contamination densities $\left(\mathrm{Bq} / \mathrm{cm}^{2}\right)$ over time since 11th April 2011 inside the controlled areas. The values less than detection limit are tentatively shown at detection limit in this figure. Dashed line indicates the detection limit (0.35 $0.49 \mathrm{~Bq} / \mathrm{cm}^{2}$ ).

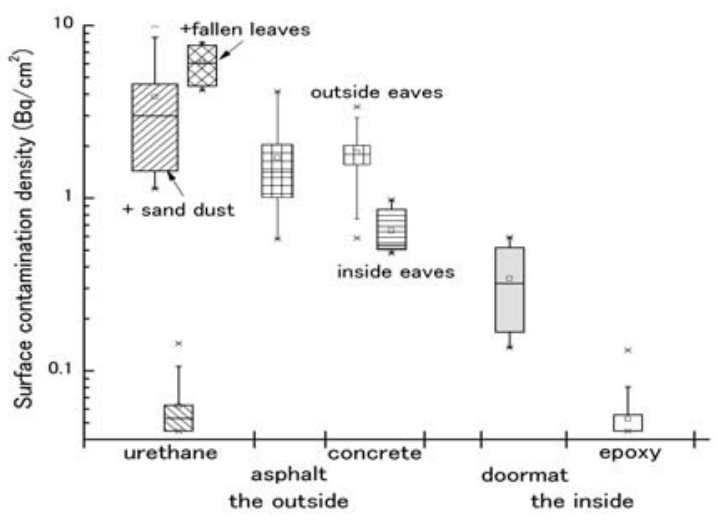

Figure 4. Box plot of the surface contamination densities $\left(\mathrm{Bq} / \mathrm{cm}^{2}\right)$ inside and outside the FRS in November 2011. Urethane was coated on the roof (see Figure 2). As for concrete, the surface inside eaves had been little exposed to rainfall directly.

Measured points were both surfaced with asphalt (see Figure 2). These showed that dozens of times higher contamination was remained outside. The ${ }^{134} \mathrm{Cs} /{ }^{137} \mathrm{Cs}$ ratio was about 0.9 tentatively (without coincidence-summing correction). This was in good agreement with measurement results around the FDNPS, taking into account the radioactive decay correction.

Figure 4 also shows the contamination levels on surfaces made of different materials outside the FRS. On the urethane surface of the outside, measurement results varied among the points. Results obtained at places where sand dust or fine fragment of fallen leaves and needles had gathered due to weathering were much higher. This demonstrated that most of radioactive contaminants came from the sand dust or fallen leaves on water-shedding, smooth surface made of urethane. In contrast, contaminations on asphalt or concrete were the same level with an order of magnitude (a few $\mathrm{Bq} / \mathrm{cm}^{2}$ ), which was consistent with the results described above using the Ge detector. With regard to the concrete surface, discontinuous change for contamination level were found, which were totally corresponded to the boundaries exposed to rainfall directly due to the eaves (see also Figure 4). This result might support that the 
wet deposition was dominant for radiocaesium as described previously [3] and radiocaesium deposited on concrete might hardly migrate during this time scale.

\subsection{Evaluation of the effect of measures}

Since the half-lives of ${ }^{131} \mathrm{I},{ }^{132} \mathrm{Te}$ and ${ }^{132} \mathrm{I}$ are comparatively short (8.04 days, 3.20 days and 2.30 hours, respectively), the authors waited for sufficient decays of these contaminants. Thus, the operation was limited for about two months. At the end of May 2011 these nuclides have not been observed in environmental monitoring in NSRI [2]. Moreover, deposited ones were enough to decay in May from radionuclide analysis. Waiting the decays of short-lived contaminants would lead to save resources. After short-lived contaminants disappeared, attention was drawn to decontamination of radiocaesiums $\left({ }^{134} \mathrm{Cs}\right.$ and $\left.{ }^{137} \mathrm{Cs}\right)$. Wiping out with a wet cloth and steam cleaners was found to be not only efficient for decontamination of floors inside controlled areas (decontamination factors were estimated to be $\sim 1.5$ for a wet cloth and 1.2-2.2 for steam cleaners) but also effective for reducing waste.

From the measurement results for the urethane surface outside the FRS shown in Figure 3, the migration of dust binding radiocaesium might cause the contamination of controlled areas. Dust (including soil particles and fine fragment of fallen leaves) were sampled along the assuming entry pathways in December 2011. Table 1 shows the measurement results of these samples using a Ge detector. Radiocaesium activities at the shielding door rail of the controlled area boundary were found to be comparable with those from the outside of the FRS. These results demonstrated that the dust blowing in could contribute to the contamination of the controlled areas. In addition, higher concentration at the doormat than those inside suggested that the sand dust attached to the shoes was another pathway to contaminate.

Table 1. Radiocaesium activities of dust along the assuming entry pathways in December 2011.

\begin{tabular}{ccrr}
\hline \multirow{2}{*}{ Sampling location } & \multicolumn{2}{c}{ Activity $(\mathrm{Bq} / \mathrm{g})$} \\
\cline { 3 - 4 } Outside & North & \multicolumn{1}{c}{${ }^{137} \mathrm{Cs}$} & \multicolumn{1}{c}{${ }^{134} \mathrm{Cs}$} \\
& South & $13.01 \pm 0.11$ & $16.63 \pm 0.07$ \\
Boundary & Door rail \#3 & $20.84 \pm 0.28$ & $9.25 \pm 0.05$ \\
& Door rail \#4 & $9.39 \pm 0.08$ & $6.62 \pm 0.05$ \\
& Doormat & $0.82 \pm 0.02$ & $0.56 \pm 0.02$ \\
Inside & $\# 3$ & $0.51 \pm 0.03$ & $0.37 \pm 0.04$ \\
& $\# 4$ & $0.31 \pm 0.01$ & $0.22 \pm 0.01$ \\
\hline
\end{tabular}

Prevention against entry of dust was the key for the practice. Among practices as measures for reducing contamination levels, sealing up doors, changing shoes and monitoring stuff were inevitable practices. Repeated wiping out and monitoring of the surface contamination density were found to be essential measures as well. In particular, monitoring results make it possible to revise these practices periodically.

\section{Summary and conclusion}

Even as far as $120 \mathrm{~km}$ away from the FDNPS, inside the controlled areas of the FRS was contaminated due to the Fukushima nuclear accident. However, the facility had to be kept running even under contaminated environment by establishing a scheme of practices for reducing the contamination. A strategy against the existing contaminated situation was developed, before practicing decontamination and prevention measures against radioactive contaminants. Among measures, waiting until short-lived radioiodines decay and wiping out with a wet cloth and/or steam cleaners were found to be effective for decontamination inside the controlled areas, resulting in less than about $0.4 \mathrm{~Bq} / \mathrm{cm}^{2}$. Under contaminated environment, prevention against entry of contaminants was the key practice. Practices for preventing dust from coming into, changing shoes, and removal of dust were found to be very effective. Monitoring surface contamination density and reviewing practices based on measurement results could make these practices periodically revised as well.

These practices enabled us to operate the FRS as much as usual since August 2011. Measures will be over, when asphalts and contaminants on concrete around the FRS are to be removed for fear of their erosion.

\section{Acknowledgements}

The authors wish to thank Mr. M. Yoshizawa (JAEA) for the helpful comments to prepare this paper. The authors also thank Mr. M. Tsutsumi (JAEA), Mr. Y. Kobayashi (JCAC), Mr. S. Tamura (IRM) and Mr. T. Sawahata (IRM) for the measurements of radioactivity in samples. The authors are also grateful to all the members of the FRS for their assistance.

\section{References}

[1] M. Takeyasu, M. Nakano, H. Fujita, A. Nakada, H. Watanabe, S. Sumiya and S. Furuta, Results of environmental radiation monitoring at the Nuclear Fuel Cycle Engineering Laboratories, JAEA, following the Fukushima Daiichi Nulclear Power Plant accident, J. Nucl. Sci. Technol. 49 (2012), pp. 281-286.

[2] T. Ohkura, T. Oishi, M. Taki, Y. Shibanuma, M. Kikuchi, H. Akino, Y. Kikuta, M. Kawasaki, J. Saegusa, M. Tsutsumi, H. Ogose, S. Tamura and T. Sawahata, Emergency monitoring of environmental radiation and atmospheric radionuclides at Nuclear Science Research Institute, JAEA following the accident of Fukushima Daiichi Nuclear Power Plant, JAEA-Data/Code 2012-010, Japan Atomic Energy Agency, (2012).

[3] Y. Morino, T. Ohara and M. Nishizawa, Atmospheric behavior, deposition, and budget of radioactive materials from the Fukushima Daiichi nuclear power plant in March 2011, Geophys. Res. Lett. 38 (2012), pp. 1-28. 